\title{
DESIGN AND CHARACTERIZATION OF CANDESARTAN CILEXETIL ORAL NANOEMULSION CONTAINING GARLIC OIL
}

\author{
ABULFADHEL JABER NEAMAH AL-SHAIBANI ${ }^{a^{*}}$, KARRAR MOHAMMED HASAN AL-GBURI ${ }^{b}$, KARRAR TALIB \\ KHUDHAIR ALBO HAMRAHa, ALI MOHAMMED ABD ALRIDHA ${ }^{\mathrm{b}}$
}

aDepartment of Pharmaceutics, Faculty of Pharmacy, University of Kufa, Najaf, Iraq, bepartment of Clinical Pharmacy, Faculty of Pharmacy, University of Kufa, Najaf, Iraq

Email: abulfadhelj.alshaibani@uokufa.edu.iq

Received: 24 Jul 2019, Revised and Accepted: 23 Sep 2019

ABSTRACT

Objective: This study was designed to prepare and characterize oil in water (o/w) nanoemulsion of candesartan cilexetil for oral administration. Preparation of candesartan cilexetil as nanoemulsion could increase its water solubility and thus could enhance its bioavailability.

Methods: Aqueous titration method was used to construct the pseudo-ternary phase diagrams of nanoemulsion (NE) consisting of oil, various weight ratios of surfactant and co-surfactant ( $\mathrm{S}$ mix), and deionized water. Different characterization techniques were conducted on the prepared nanoemulsions to obtain the optimized formula.

Results: Characterizations of formula NE-4 (consists of $0.16 \%$ of candesartan cilexetil, $10 \%$ of garlic oil, $35 \%$ of S mix (3:1) and $54.84 \%$ of deionized water) revealed the following characteristics: droplet size range $(95-139 \mathrm{~nm})$, polydispersity index (0.14), zeta potential value (-41.06 $\mathrm{mV}$ ) and $\mathrm{pH}$ value (6.71), which are suitable for oral administration. Candesartan cilexetil in vitro release from this formula was significantly high $(\mathrm{P}<0.05)$ and scanning probe microscopy $(\mathrm{SPM})$ study confirmed that the optimized formula (NE-4) was in nano-scale.

Conclusion: Nanoemulsion formula 4 (NE-4) of candesartan cilexetil is the optimized formula and it could be a promising formula for improving the water solubility of candesartan cilaxetil.

Keywords: Oral nanoemulsion, Pseudo-ternary phase diagram, Biopharmaceutics classification system (BCS), Candesartan cilexetil, Solubility

(C) 2019 The Authors. Published by Innovare Academic Sciences Pvt Ltd. This is an open access article under the CC BY license (http://creativecommons.org/licenses/by/4.0/) DOI: http://dx.doi.org/10.22159/ijap.2019v11i6.35066

\section{INTRODUCTION}

Oral conventional dosage forms are designed to provide a rapid onset via an immediate release of the active ingredient after administration. The desired therapeutic action, which can be achieved from these conventional drug delivery system, is based on the bioavailability of drugs. Bioavailability of immediate-release products is influenced by two important drug characteristics, which are water-solubility and permeability. Dissolution rate in the conventional dosage forms that contain a drug with low water solubility would be low, hence the bioavailability may be affected due to lower absorption across the gastrointestinal tract [1]. Based on permeability and water solubility, four classes of drugs are classified by Biopharmaceutics Classification System (BCS) into class I includes drugs with high permeability and high water solubility, class II includes drugs with high permeability and low water solubility, class III includes drugs that possess low permeability and high water solubility and class IV includes drugs with low permeability and low water solubility [2].

Enhancing water solubility of drugs belonging to class II using different techniques, such as self-emulsification, particle size reduction, and nanotechnology approaches, have the potential to improve absorption and thus enhance oral bioavailability of these drugs [3]. An example of these techniques is a nanoemulsion, which is a colloidal dispersion system consisting of oil, water, and surfactant and co-surfactant [4]. This system (nanoemulsion) is a thermodynamically stable system and is available in three different types: oil in water $(\mathrm{o} / \mathrm{w})$, water in oil (w/o) and bi-continuous nanoemulsions, where the microdomains of the two phases (water and oil) are inter-dispersed within the system [4]. Stabilization of all three nanoemulsion types is achieved via the presence of a good amount of surfactant and co-surfactant [4]. Based on the fact that this system (nanoemulsion) is prepared with a little energy input and has a long shelf life, it has a higher thermodynamic stability and solubilization capacity than other micellar solutions. Additionally, nanoemulsion can enhance the transport characteristic of drug, which is crucial for sustained and targeted drug delivery owing to their numerous interfacial area associated with this system [5]. Examples of successful implementation of nanoemulsion in enhancing water solubility have been reported previously, which were; oral nanoemulsion of rosuvastatin, rifampicin, and pterostilbene [6-8].

Candesartan cilexetil, a selective angiotensin II receptor subtype inhibitor, belongs to BCS class II with low water solubility and high permeability, while its oral bioavailability is only $14-40 \%$ [9]. Hence, this study was aimed to develop, optimize, and characterize candesartan cilexetil oral oil in water $(\mathrm{o} / \mathrm{w})$ nanoemulsion to improve its solubility and possibly the bioavailability.

\section{MATERIALS AND METHODS}

\section{Materials}

Pure candesartan cilexetil powder was purchased from Hyper chem company, China. Tween 20, tween 60 and tween 80 were purchased from Thomas baker (chemicals) Pvt Ltd, India. Olive oil was supplied by Pomace olive oil, oilex, S. A, Spain. Polyethylene glycol 400 and propylene glycol were supplied by $\mathrm{M} / \mathrm{s}$ provizer pharma, India. Ethanol was supplied by Avantor performance materials, Norway. Garlic oil and peppermint oil were purchased from Al-Emad Company, Iraq. Soybean oil was obtained from Genuine chemicals, India. Castor oil and deionized water were supplied by Al-Basheer company for chemical and laboratory materials, Baghdad, Iraq.

\section{Methods}

\section{Melting point measurement}

Candesartan cilexetil melting point was recorded by inserting a small amount of pure powdered drug into one side of a sealed capillary glass tube. By using a digital melting point instrument, the temperature of melting was recorded when all the powdered drug has melted [10].

\section{Study of differential scanning calorimetry}

Differential scanning calorimeter(DSC) technique was made by placing a sample of the drug ( $5 \mathrm{mg}$ ) in the aluminum pan of DSC-60 Shimadzu. Analysis of this technique was made by using nitrogen at 
a rate of $10 / \mathrm{min}$ as inflow gas with heating range $50-250$. DSC thermogram of candesartan cilexetil was recorded [11].

\section{Study of saturated solubility}

The saturated solubility of candesartan cilexetil was determined in various surfactants (tween 20, tween 60 and tween 80), cosurfactants (polyethylene glycol 400 and propylene glycol) and oils (olive oil, garlic oil, peppermint oil, castor oil, and Soybean oil). Excess amount of powdered drug was added to $2 \mathrm{ml}$ of each surfactant, co-surfactant, and oil in tightly closed plain tubes. The tubes were placed in an isothermal shaker water bath at $25 \pm 0.5$ for $48 \mathrm{~h}$. Then the samples were centrifuged at $2000 \mathrm{rpm}$ for $10 \mathrm{~min}$ and supernatants for each sample were filtered by using filter membrane $(0.45 \mu \mathrm{m})$. After dilution of filtrate with ethanol, solubility was measured using a UV-visible spectrophotometer in determined maximum wavelength [12].

\section{Construction of pseudo-ternary phase diagrams}

Aqueous titration method was utilized to determine the components of pseudo-ternary phase diagrams. These components include a mixture of surfactant and co-surfactant ( $\mathrm{S}$ mix), oil and deionized water. Different weight ratios $(2: 1,3: 1$, and $4: 1)$ were used for the mixing of surfactant and co-surfactant (S mix). Oil and S mix was blended in different weight ratios until the maximum ratio of oil and $\mathrm{S}$ mix was obtained. Fifteen different combinations of S mix and oil were prepared, then these combinations slowly titrated with deionized water and visual inspection was made for transparency. The titration was stopped when clear and transparent oil in water (o/w) nanoemulsion was produced [13].

\section{Preparation of the candesartan cilexetil loaded nanoemulsions}

Candesartan cilexetil pure powder was dissolved in the oil that had the highest solubility for the drug, after that the quantity of S mix prepared from mixing of surfactants with co-surfactant was added to the oil loaded with the drug. Vortex mixer was used to blend the components of the whole mixture. Then titration of deionized water (drop by drop) on the mixture was made until clear $(0 / w)$ nanoemulsion is produced [14].

\section{Thermodynamic stability tests of the prepared nanoemulsions}

Centrifugation test: Nanoemulsions were centrifuged for $15 \mathrm{~min}$ at $2000 \mathrm{rpm}$ and checked for phase separation or cracking [15].

Freezing-thawing test: This test involved exposure of nanoemulsions to different temperatures, which were $21{ }^{\circ} \mathrm{C}$ and freeze using a refrigerator with no less than $24 \mathrm{~h}$ for each temperature.

Heating-cooling test: This test was made by keeping nanoemulsions at $40{ }^{\circ} \mathrm{C}$ and $0{ }^{\circ} \mathrm{C}$ by the refrigerator. The time for each temperature was no less than $48 \mathrm{~h}$. In this test, the cracking effect on nanoemulsion stability was reported

\section{Characterization of nanoemulsion}

\section{Droplet size measurement}

Droplet size was measured using particle size analyzer ABT-9000 nanolaser. The droplet size and the plot for the distribution of the droplets were reported [16].

\section{Polydispersity index (PDI) measurement}

(PDI) measurement was made utilizing particle size analyzer ABT-9000 nanolaser. This PDI determination indicates the distribution of droplets is within the nanoemulsion scale and determines the uniformity of droplets, i.e. higher value indicates lower uniformity [17].

\section{Zeta potential (ZP) measurement}

Determination of zeta potential was made using zeta sizer instrument (Brookhaven). Zeta potential refers to the stability of colloidal dispersions, hence it describes the charge on the droplet surface [18].

\section{Percent of transmittance measurement (\% T)}

This measurement was performed using a UV-visible spectrophotometer (Emc Lab. UV-61 Double beam, Germany). The transmittance of the prepared nanoemulsions was measured at 650 $\mathrm{nm}$ using deionized water as a blank [19].

\section{pH measurement}

$\mathrm{pH}$ of the prepared nanoemulsions was reported using digital $\mathrm{pH}$ meter (BP 3001, Trans instruments, Singapore), the measurement was made in triplicate [20].

\section{Viscosity measurement}

Viscosity measurement was made using NDJ-digital viscometer (spindle no. 1) at 25. The viscosity was measured without making any formulation dilution [21].

\section{In vitro release study}

In vitro release of candesartan cilexetil nanoemulsion was studied using dissolution apparatus USP-II (Copley dissolution tester DIS 8000, UK) with dialysis bag. Amount of candesartan cilexetil was 8 $\mathrm{mg}$ in each nanoemulsion formula $(5 \mathrm{~g})$. Each formula was placed in the dialysis bag and the dialysis bag was immersed in $900 \mathrm{ml}$ of dissolution medium. The dissolution medium was phosphate buffer (pH 6.8). The apparatus was set at $37 \pm 0.5$ with rotation velocity of 50 rpm for $2 \mathrm{~h}$. One Sample (5 ml) was withdrawn every $15 \mathrm{~min}$ for $2 \mathrm{~h}$ and was replenished by $5 \mathrm{ml}$ of fresh medium to maintain sink condition. All samples withdrawn were filtered using filter membrane $(0.45 \mu \mathrm{m})$. Then, samples were analyzed using a UVvisible spectrophotometer at $255 \mathrm{~nm}$ to determine the candesartan cilexetil amount in the formula [22].

\section{Kinetics and mechanism of drug release}

Various kinetics models were applied to the data obtained from in vitro release study to determine kinetics and mechanisms of drug release. These models are zero-order, first-order, Higuchi's and Korsmeyer's model [23].

\section{Scanning probe microscopy (SPM)}

SPM (triple probe microscope) study was made to show the morphology of the droplets and droplets distribution within the prepared system. A drop of nanoemulsion was placed on a glass slide where detection was made [24].

\section{Statistical analysis}

Analysis of variance test (ANOVA) was used to analyze the data. Variables with P-value $>0.05$ were considered statistically insignificant.

\section{RESULTS AND DISCUSSION}

\section{The melting point of the drug}

The melting point of candesartan cilexetil was found in the range of (171-172). This result was similar to that reported in the literatures, which indicates the purity of the powdered drug used in the study [25].

\section{Differential scanning calorimetry (DSC)}

Candesartan cilexetil pure powder produced a sharp peak at 172.29 [26]. This reading corresponds with the measured melting point of candesartan cilexetil. DSC thermogram explained in fig. 1.

\section{Saturated solubility}

The preparation of stable nanoemulsion requires a suitable selection of components forming the formulas. Using a saturated solubility study of candesartan cilexetil in different oils, surfactants, and cosurfactants, the main components of the formulation can be selected. Hence, the formulation components which have the highest solubility for candesartan cilexetil were chosen as the main components in the preparation. Garlic oil had the highest solubility for the drug as compared with other oils used in this study, hence it was used as an oil phase in the formulation. Similarly, Tween 80 and polyethylene glycol 400 (PEG400) had the highest solubility for the candesartan cilexetil, hence tween 80 was used as surfactant and PEG400 was used as co-surfactant in the formulation [7]. The results of the saturated solubility of candesartan cilexetil in various oils, surfactants, and co-surfactants are explained in fig. 2. 


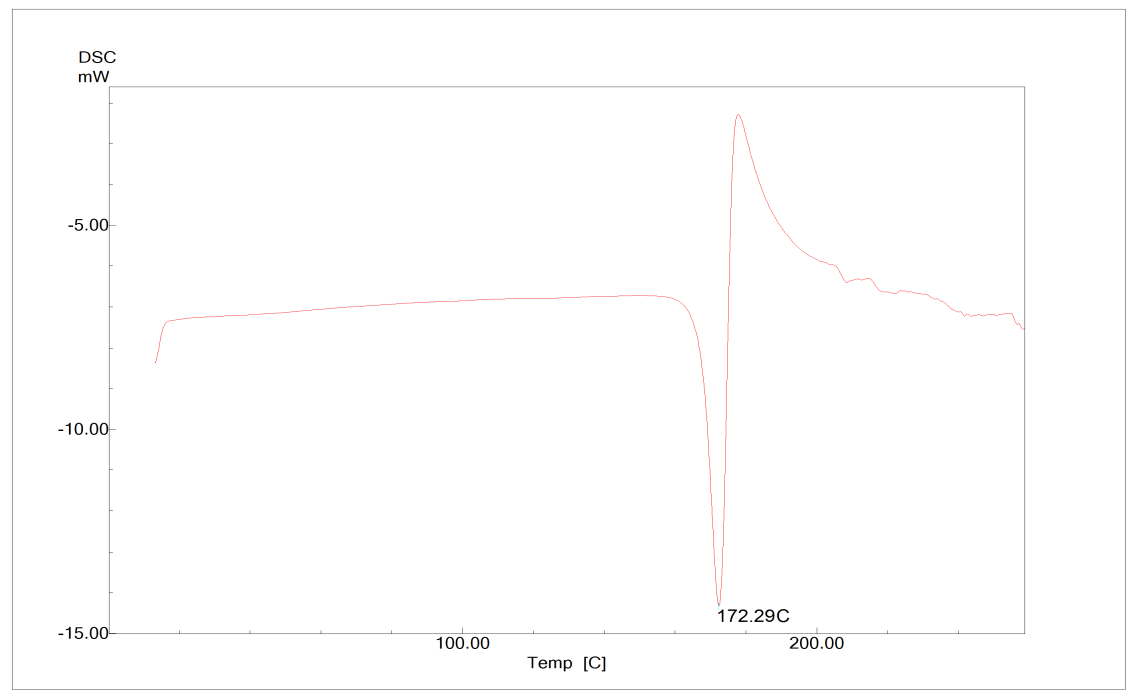

Fig. 1: DSC thermogram of candesartan cilexetil pure powder

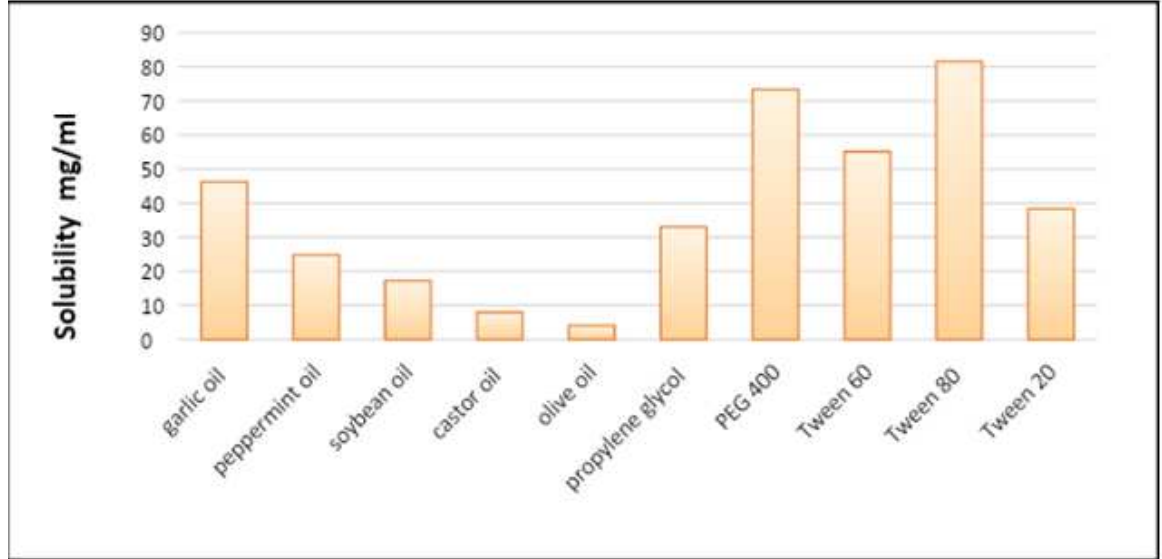

Fig. 2: Saturated solubility of candesartan cilexetil pure powder in different oils, surfactants, and co-surfactants

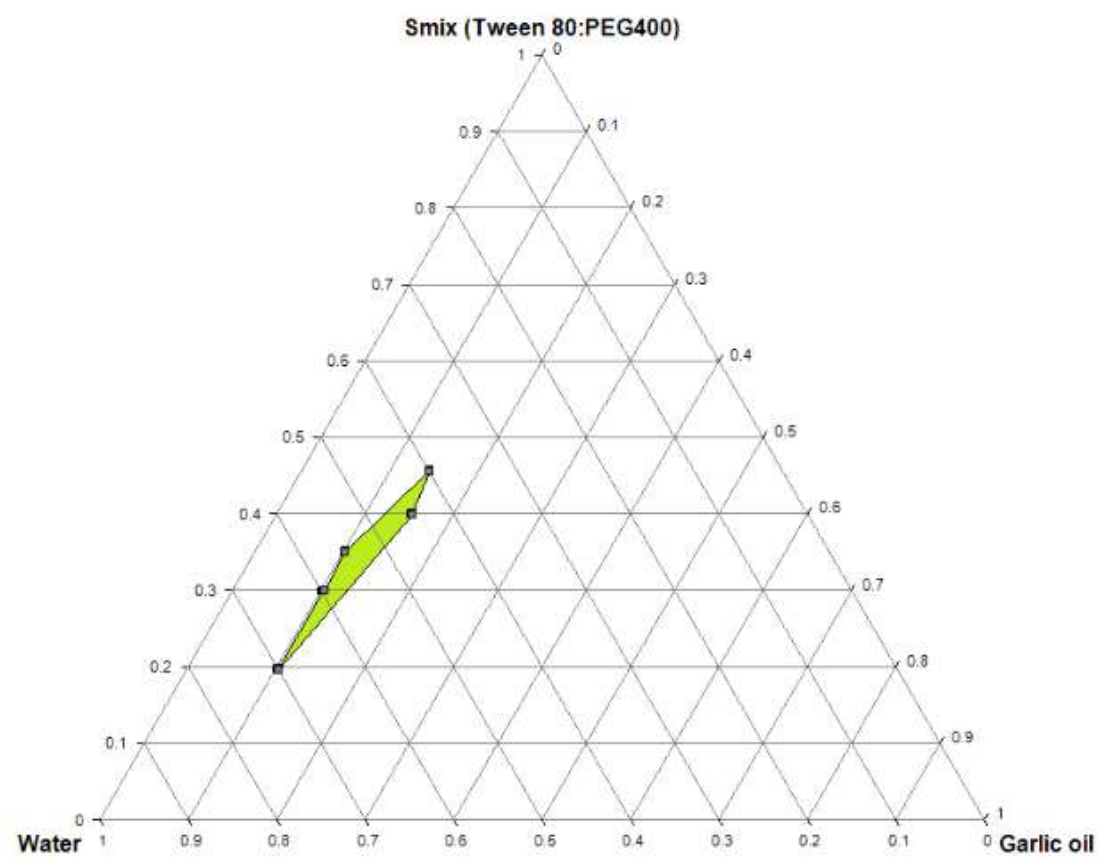

Fig. 3: Pseudo-ternary phase diagram of garlic oil, Smix 2:1 and deionized water 


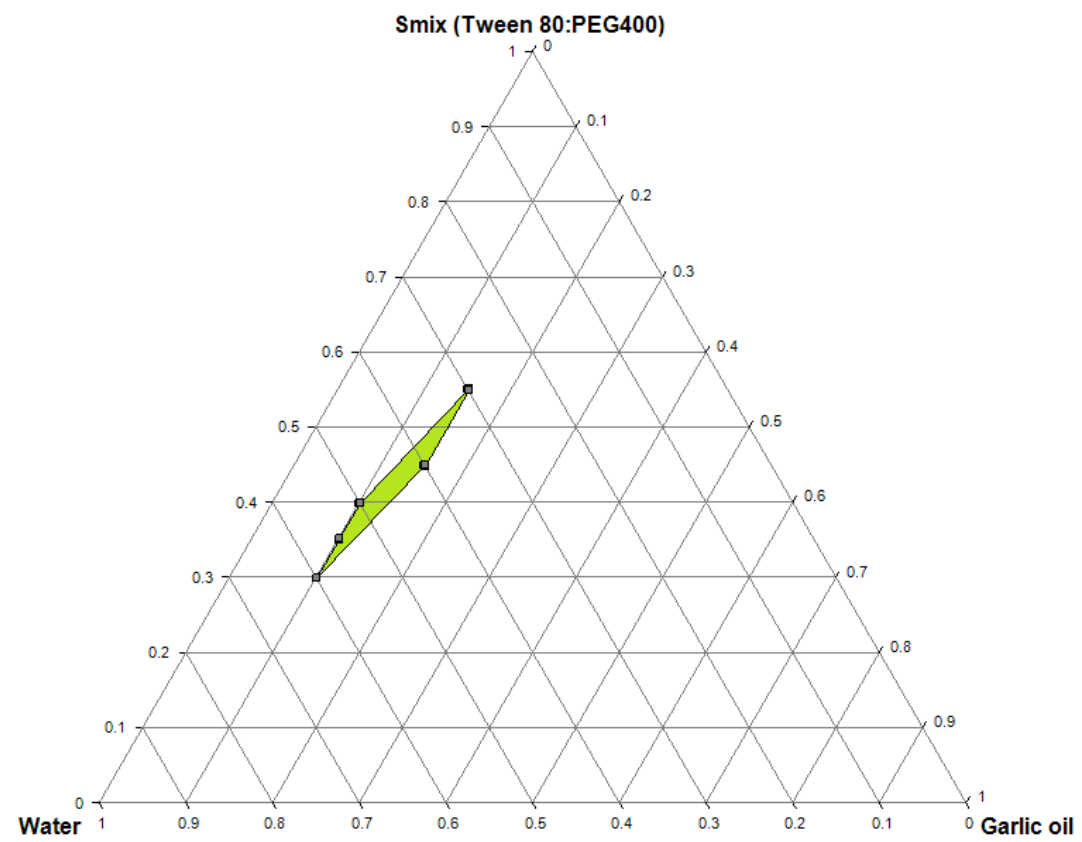

Fig. 4: Pseudo-ternary phase diagram of garlic oil, Smix 3:1 and deionized water

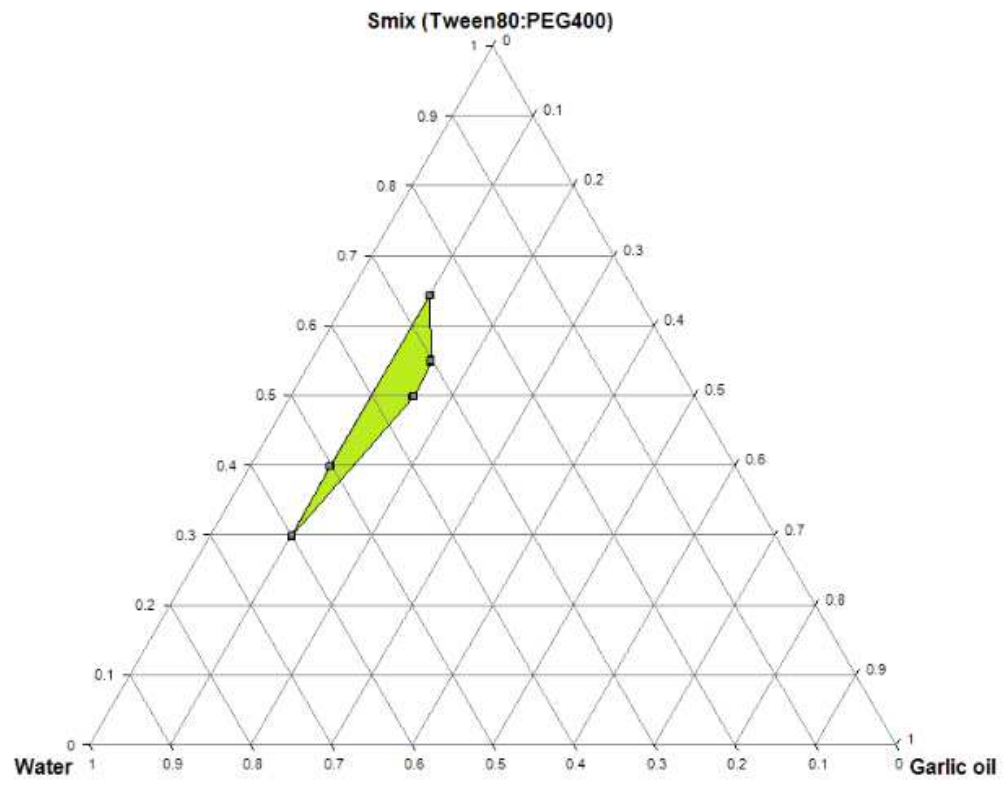

Fig. 5: Pseudo-ternary phase diagram of garlic oil, Smix 4:1 and deionized water

\section{Construction of pseudo-ternary phase diagrams}

Pseudo-ternary phase diagrams were plotted using the component which had the highest solubility for candesartan cilexetil. Garlic oil was chosen as the oil phase both because of its high solubility to the drug and its benefits to patients with cardiovascular diseases, especially hypertension [27], which is one of the most important clinical indication of candesartan cilexetil. Tween 80 as a surfactant, polyethylene glycol 400 (PEG400) in S mix ratio (2:1, 3:1 and 4:1) and deionized water were selected as the aqueous phase in the formulation. Pseudo-ternary phase diagrams with different S mix ratios are shown in fig. 3-5, where the colored area in the plot was regarded as the area of nanoemulsion.

\section{Preparation of candesartan cilexetil loaded nanoemulsion}

Candesartan cilexetil loaded nanoemulsions were prepared by dissolving $0.16 \mathrm{~g}$ of the drug in the determined quantities of oil and $\mathrm{S}$ mix to prepare a formula of $100 \mathrm{~g}$, which means that $8 \mathrm{mg}$ of drug was in a formula of $5 \mathrm{~g}$. Drug-loaded nanoemulsions are explained in table 1.

Thermodynamic stability tests of the prepared nanoemulsions

All preparations of drug-loaded nanoemulsions were successfully passed through the tests of dispersion stability, where the appearance of phase separation or cracking effect was not reported. Six nanoemulsions with different $\mathrm{S}$ mix ratios were selected for 
characterization study. These nanoemulsions were F1 (NE-1), F2 (NE-2), F6 (NE-3), F7 (NE-4), F11 (NE-5) and F12 (NE-6). The selection was made based on the low percentage of S mix and high percentage of deionized water [28].

Table 1: Composition of candesartan cilexetil loaded nanoemulsions (F1-F15)

\begin{tabular}{|c|c|c|c|c|c|}
\hline$S$ mix ratio & Formula code & $\begin{array}{l}\text { Garlic oil } \\
\% \mathrm{w} / \mathrm{w}\end{array}$ & $\begin{array}{l}\mathrm{S} \operatorname{mix}(\mathrm{S} / \mathrm{CoS}) \\
\% \mathrm{w} / \mathrm{w}\end{array}$ & $\begin{array}{l}\text { Candesartan cilexetil } \\
\text { Gm/100 gm }\end{array}$ & Deionized water \%w/w \\
\hline & F1 & 10 & $20(13.33: 6.66)$ & 0.16 & 69.84 \\
\hline \multirow[t]{5}{*}{$2: 1$} & F 2 & 10 & $30(20: 10)$ & 0.16 & 59.84 \\
\hline & F 3 & 10 & $35(23.33: 11.66)$ & 0.16 & 54.84 \\
\hline & F 4 & 15 & $40(26.66: 13.33)$ & 0.16 & 44.84 \\
\hline & F 5 & 15 & $45(30: 15)$ & 0.16 & 39.84 \\
\hline & F 6 & 10 & $30(22.5: 7.5)$ & 0.16 & 59.84 \\
\hline \multirow[t]{5}{*}{$3: 1$} & F 7 & 10 & $35(26.25: 8.75)$ & 0.16 & 54.84 \\
\hline & F 8 & 10 & $40(30: 10)$ & 0.16 & 49.84 \\
\hline & F 9 & 15 & $45(33.75: 11.25)$ & 0.16 & 39.84 \\
\hline & F 10 & 15 & $55(41.25: 13.75)$ & 0.16 & 29.84 \\
\hline & F 11 & 10 & $30(24: 6)$ & 0.16 & 59.84 \\
\hline \multirow[t]{4}{*}{$4: 1$} & F 12 & 10 & $40(32: 8)$ & 0.16 & 49.84 \\
\hline & F 13 & 15 & $50(40: 10)$ & 0.16 & 34.84 \\
\hline & F 14 & 15 & $55(44: 11)$ & 0.16 & 29.84 \\
\hline & F 15 & 10 & $65(52: 13)$ & 0.16 & 24.84 \\
\hline
\end{tabular}

\section{Characterization of nanoemulsions}

\section{Droplet size measurement}

The results of droplet size measurement of the six drug-loaded nanoemulsions are shown in table 2 . The results indicate that all the nanoemulsions were observed in a nano-size scale. Furthermore, as the ratio of $\mathrm{S}$ mix increases, the droplet size decreases. Such observations can be attributed to the fact that the lipophilic tail of surfactant (tween 80) in the drug-loaded nanoemulsions is pulled toward the drug and the drug makes an insertion of co-surfactant between the cavities of surfactant causing a condensation of interfacial film, stabilization, and production of droplets in a small size [29]. According to the analysis of variance (ANOVA) test, there was a significant effect of S mix ratio on the droplet size (P-value $<0.05)$.

\section{Polydispersity index (PDI) measurement}

The results of the PDI measurement of the six drug-loaded nanoemulsions are explained in table 2 . A typical range of PDI of $(0-$
1) indicates the uniformity of droplet size distribution within the formulations. In this study, the values of the drug-loaded nanoemulsions PDI were less than one, which explains the uniformity and distribution of the droplets dispersed in the garlic oil globules within the nanoemulsions [30].

\section{Zeta Potential (ZP) Measurement}

The results of the ZP measurement of the six drug-loaded nanoemulsions are explained in table 2. Zeta potential is an important indicator of colloidal dispersions stability. Rule of thumb explains the zeta potential effect on the stability of nanoemulsion. This rule indicates that: fast droplets aggregation occurs when values of zeta potential are $(-5$ to $+5 \mathrm{mV})$, values of $(\leq-20$ to $\geq+20 \mathrm{mV})$ indicate shortterm stability, while values of $(\leq-30$ to $\geq+30 \mathrm{mV})$ indicate good system stability. Excellent stability within formulation can be obtained when $\mathrm{ZP}$ values in the range of $(-60$ to $+60 \mathrm{mV})$ [31]. In this study, NE-1 and NE-2 were within short stability, while NE-3, NE-4, NE-5, and NE-6 were in the range of good stability.

Table 2: Characteristics of nanoemulsions (Droplet size, PDI, ZP)

\begin{tabular}{llll}
\hline NE-code & Droplets size range (nm) & Polydispersity index (PDI) & Zeta potential (ZP) (mv) \\
\hline NE 1 & $315-397$ & 0.09 & -23.12 \\
NE 2 & $281-397$ & 0.06 & -28.70 \\
NE 3 & $223-315$ & 0.01 & -35.10 \\
NE 4 & $95-139$ & 0.14 & -41.06 \\
NE 5 & $37.4-123$ & 0.03 & -45.53 \\
NE 6 & $16.6-93.2$ & 0.15 & -39.13 \\
\hline
\end{tabular}

\section{Percent of transmittance measurement (\%T)}

Percent of transmittance of the six drug-loaded nanoemulsions are illustrated in table 3 . Values of all nanoemulsions were higher and closer to $100 \%$, which indicates the clarity and transparency of the nanoemulsions [5]. The highest value of percent of transmittance was $(99.313 \pm 0.011 \%)$, which belongs to the formula (NE-4). The lower value of $(\% \mathrm{~T})$ was $(98.151 \pm 0.102)$, which belongs to the formula (NE-1). According to (ANOVA) test, there was no significant difference (P-value>0.05) in the percent of transmittance values among all the six drug-loaded nanoemulsions.

\section{pH measurement}

The results of the $\mathrm{pH}$ measurement of all six drug-loaded nanoemulsions are explained in table 3 . The $\mathrm{pH}$ values of all nanoemulsions were higher than (5.5), which can be attributed to the high percentage of the aqueous phase and the slight basic properties of an oil phase (garlic oil). This could convey the suitability of the formulations for oral administration. According to (ANOVA) test, there was no significant difference (P-value $>0.05$ ) in $\mathrm{pH}$ values between all drug-loaded nanoemulsions.

\section{Viscosity measurement}

Viscosity values of all drug-loaded nanoemulsions are shown in table 3 . The viscosity of all nanoemulsions was found in the range of (58.232 $\mathrm{mPa}$. s) for NE-2 and (36.175 mPa. s) for NE-4. There was a significant difference $(\mathrm{P}$-value $<0.05)$ in the viscosity values of the nanoemulsions. This reveals that all the nanoemulsions are easily poured and are suitable for an oral administration.

\section{In vitro release study}

The release of the prepared candesartan cilexetil nanoemulsions (NE-1-NE-6) is illustrated in fig. 6. Drug release profile of the nanoemulsions (NE-1, NE-2, NE-3, NE-4, NE-5 and NE-6) in the dissolution medium (phosphate buffer, $\mathrm{pH}$ 6.8) signalized drug release in an order of: NE-4>NE-3>NE-1>NE-2>NE-6>NE-5. Higher release of candesartan cilexetil was observed in NE-4 with garlic oil: S mix: deionized water of (10: 35: 54.84), in which $S$ mix was (3:1). In contrast, lower drug release was observed in NE-6 with garlic oil: $S$ mix: deionized water of $(10: 40: 49.84)$, in which $S$ mix was $(4: 1)$. It has been further noticed that as $S$ mix ratio increases, the release of the drug would increase, yet to a certain limit as was noted with $\mathrm{S}$ 
mix 2:1 and S mix 3:1. Furthermore, the release of the drug decreases with increase $S$ mix as in $4: 1$, and this can be attributed both to a high concentration of surfactant, which would make drug molecules to challenge the retarding effect resulting from the surfactant, and to the increase in the surfactant concentration, which could raise the diffusion of a drug from dialysis bag to the dissolution medium [8].

There was a significant effect $(\mathrm{P}$-value<0.05) between the concentration of surfactant and drug release.

Table 3: Characteristics of nanoemulsions, pH and \%T (mean $\pm S D, n=3)$.

\begin{tabular}{llll}
\hline NE-code & \% Transmittance (\%t) & pH & Viscosity (mPa. s) \\
\hline NE 1 & $98.151 \pm 0.102$ & $5.63 \pm 0.021$ & 51.413 \\
NE 2 & $98.211 \pm 0.034$ & $5.97 \pm 0.003$ & 58.232 \\
NE 3 & $99.012 \pm 0.032$ & $6.13 \pm 0.021$ & 40.435 \\
NE 4 & $99.313 \pm 0.011$ & $6.71 \pm 0.108$ & 36.175 \\
NE 5 & $98.843 \pm 0.103$ & $6.20 \pm 0.102$ & 46.215 \\
NE 6 & $98.511 \pm 0.120$ & $6.28 \pm 0.099$ & 43.651 \\
\hline
\end{tabular}

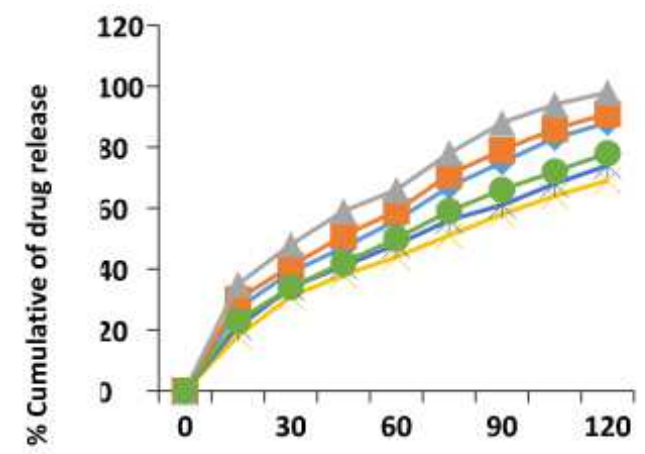

NE-1 Smix (2:1)

NE-3 Smix(3:1)

NE-4 Smix(3:1)

NE-5 Smix(4:1)

NE-6 Smix(4:1)

NE-2 Smix(2:1)

Fig. 6: In vitro release of candesartan cilexetil nanoemulsions with different Smix ratio

\section{Kinetics and mechanism of drug release}

To determine the kinetics and mechanism of drug release, release data were fitted to various kinetic models (i.e. zero order, first order, Higuchi's and Korsmeyer's model). Higher regression coefficient $\left(\mathrm{R}^{2}\right)$ values could represent the kinetics of drug release from nanoemulsions. The mechanism of drug release was determined by fitting release data to Korsmeyer-Peppa's model (equation 1). Furthermore, diffusion exponent (n) values were further determined. According to the values of the diffusion exponent (n), the mechanism of drug release can determined as following: $n$ value of 0.43 or less, the release of drug was Fickian release (diffusion)/(case I), $n$ value larger than 0.43 but less than 0.89 , the release of drug was Non-fickian release (diffusion and erosion), $n$ value of 0.89 , the release of drug was zero-order release (erosion)/(case II), and $n$ value larger than 0.89 , the release of drug would follow super release [23].

The values of the regression coefficient $\left(\mathrm{R}^{2}\right)$ and diffusion exponent (n) of candesartan cilexetil nanoemulsions were explained in table 4 . In this study, higher regression coefficient $\left(R^{2}\right)$ values were obtained in Higuchi's model; hence the kinetics of drug release in all nanoemulsions would follow Higuchi's model. The values of diffusion exponent (n) of all nanoemulsions were significantly lower than 0.43 (P-value<0.05), which indicates that mechanism of drug release from all nanoemulsions is Fickian release (diffusion)/(case I).

\section{Equation1}

Where: $\mathrm{F}$ fraction of drug released at the time $(\mathrm{t}), \mathrm{Mt}$ is the amount of drug released at the time $(\mathrm{t}), \mathrm{M}$ is total amount in the dose age form, $\mathrm{Km}$ constant and (n) is the diffusion exponent describes the type of mechanism for drug release.

Characterization of the candesartan cilexetil nanoemulsions optimized formula

Characterizations of the candesartan cilexetil nanoemulsions indicate that NE-4 was the optimized formula. This formula had a droplet size of (95-139 nm) (fig. 7), PDI of (0.41), pH value of (6.71), viscosity value of (36.175 $\mathrm{mPa} . \mathrm{s})$, and a good drug release $(98 \%)$. These characterizations indicate that NE-4 formula was a suitable formula for oral administration. The optimized formula NE-4 had good stability based on the rule of thumb because of the zeta potential value, which was $(-41.06 \mathrm{mV})$ as explained in fig. 8 .

\section{Scanning probe microscopy (SPM) of the optimized formula}

The morphology of the optimized formula (NE-4) of candesartan cilexetil nanoemulsion was determined in this study, which was spherical in shape, the size of droplets was similar to size that obtained by particle size analyzer ABT-9000 nanolaser, aggregation doesn't present between the droplets. Hence, this optimized formula (NE-4) possess good stability. Droplets morphology of the optimized formula is explained in fig. 9, and the cumulative distribution chart of droplets within the optimized formula is shown in fig. 10.

Table 4: Kinetic analysis data of the release profile of candesartan cilexetil nanoemulsions

\begin{tabular}{llllll}
\hline NE-code & Zero-order model & First-order model & Higuchi-model & Korsmeyer-peppas model & Diffusion exponent \\
\hline & R2 & R2 & R2 & R2 \\
NE-1 & 0.956 & 0.901 & 0.991 & 0.911 & 0.29 \\
NE-2 & 0.956 & 0.899 & 0.995 & 0.908 & 0.41 \\
NE-3 & 0.946 & 0.876 & 0.992 & 0.921 & 0.36 \\
NE-4 & 0.925 & 0.823 & 0.992 & 0.901 & 0.32 \\
NE-5 & 0.957 & 0.902 & 0.997 & 0.913 & 0.19 \\
NE-6 & 0.949 & 0.895 & 0.996 & 0.909 & 0.39 \\
\hline
\end{tabular}




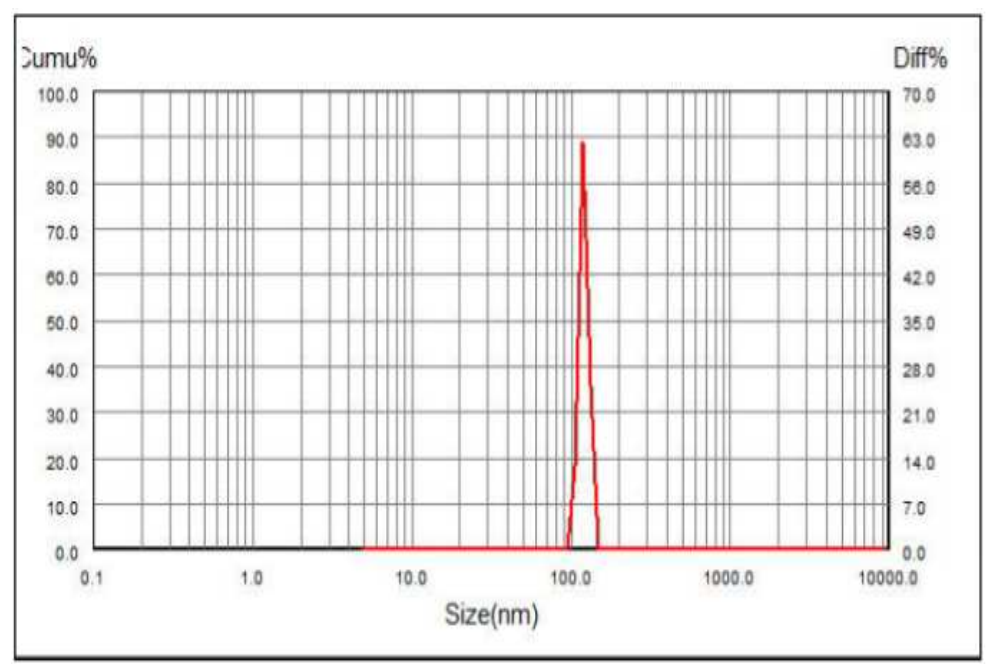

Fig. 7: Droplet size range of optimized formula (NE-4)

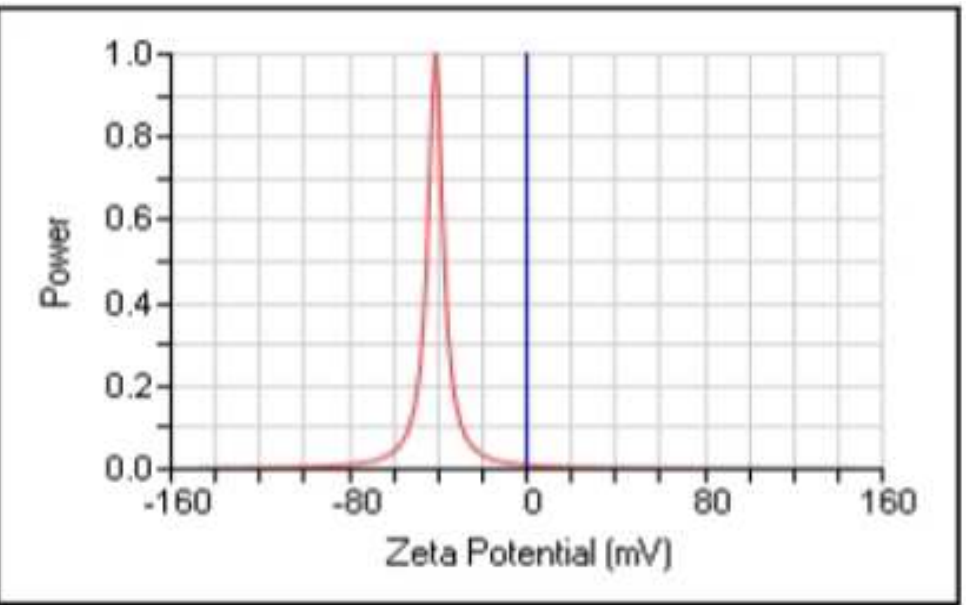

Fig. 8: Zeta potential value of optimized formula (NE-4)

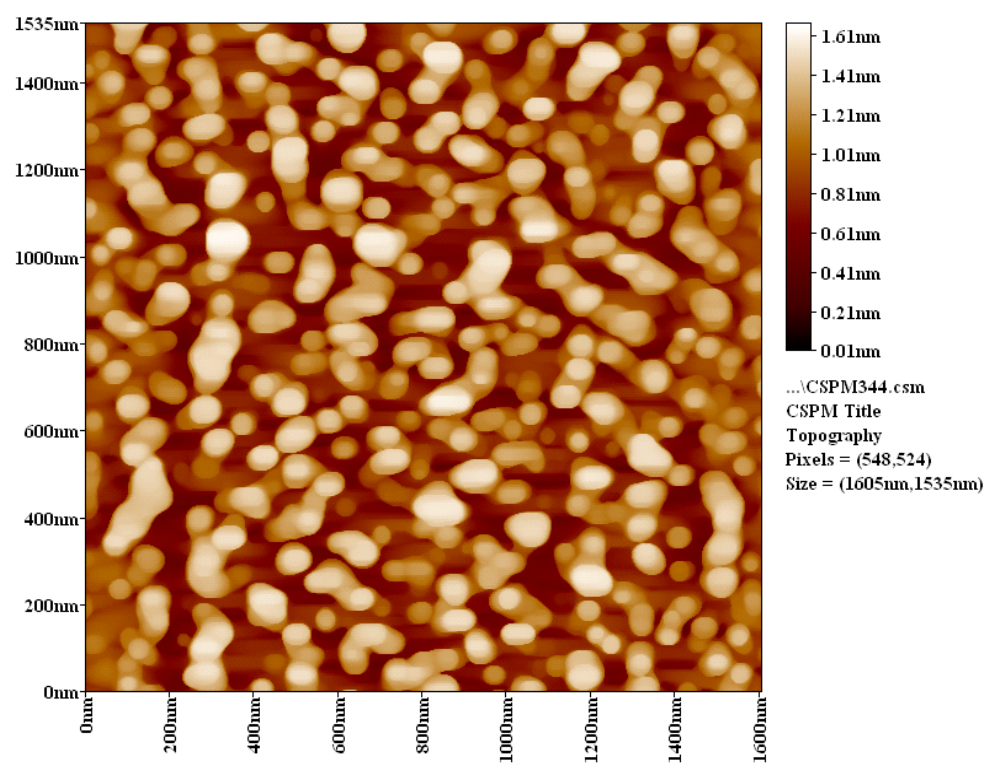

Fig. 9: Droplets morphology of optimized formula (NE-4) 
Table 5

\begin{tabular}{|c|c|c|c|c|c|c|c|c|}
\hline $\begin{array}{l}\text { Diameter } \\
(\mathrm{nm})<\end{array}$ & $\begin{array}{l}\text { Volume } \\
(\%)\end{array}$ & $\begin{array}{l}\text { Cumulation } \\
(\%)\end{array}$ & $\begin{array}{l}\text { Diameter } \\
(\mathrm{nm})<\end{array}$ & $\begin{array}{l}\text { Volume } \\
(\%)\end{array}$ & $\begin{array}{l}\text { Cumulation } \\
(\%)\end{array}$ & $\begin{array}{l}\text { Diameter } \\
(\mathrm{nm})<\end{array}$ & $\begin{array}{l}\text { Volume } \\
(\%)\end{array}$ & $\begin{array}{l}\text { Cumulation } \\
(\%)\end{array}$ \\
\hline 25.00 & 0.64 & 0.64 & 65.00 & 8.31 & 46.96 & 105.00 & 1.92 & 94.89 \\
\hline 30.00 & 1.92 & 2.56 & 70.00 & 11.82 & 58.79 & 111.00 & 1.60 & 96.49 \\
\hline 35.00 & 2.24 & 4.79 & 75.00 & 7.67 & 66.45 & 115.00 & 0.64 & 97.12 \\
\hline 40.00 & 1.28 & 6.07 & 80.00 & 8.63 & 75.08 & 120.00 & 1.60 & 98.72 \\
\hline 45.00 & 6.39 & 12.46 & 85.00 & 5.11 & 80.19 & 125.00 & 0.96 & 99.68 \\
\hline 50.00 & 5.43 & 17.89 & 90.00 & 5.75 & 85.94 & 139.00 & 0.32 & 100.00 \\
\hline 55.00 & 8.95 & 26.84 & 95.00 & 3.83 & 89.78 & & & \\
\hline 60.00 & 11.82 & 38.66 & 103.00 & 3.19 & 90.97 & & & \\
\hline
\end{tabular}

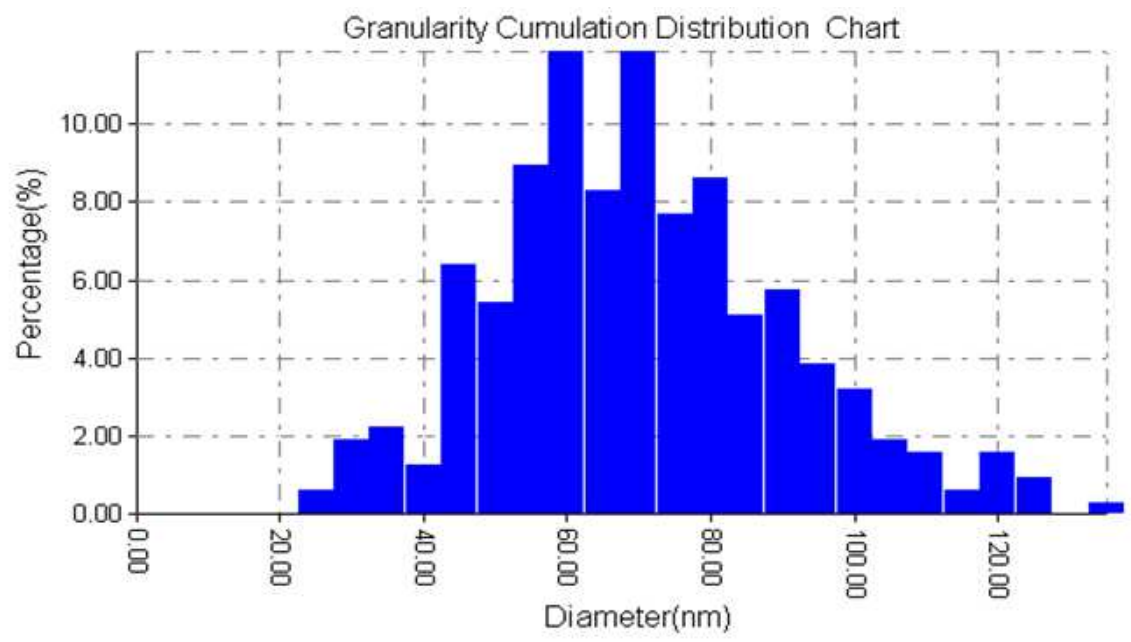

Fig. 10: Cumulative distribution chart of droplets in optimized formula (NE-4)

\section{CONCLUSION}

In summary, the nanoemulsion delivery system can be considered as an innovative way of improving the water solubility of lipophilic. In this study, formula (NE-4) with S mix of (3:1) was the optimized formula, which has shown a high solubility of candesartan cilexetil in garlic oil, and a high percent cumulative of drug release as compared with other formulas. This formular could be a promising formula to improve water solubility of candesartan cilexetil and hence, bioavailability.

\section{AUTHORS CONTRIBUTIONS}

All the authors have contributed equally

\section{CONFLICT OF INTERESTS}

\section{Declared none}

\section{REFERENCES}

1. Patel N, Naruka PS, Chauhan CS, Modi J. Formulation development and evaluation of immediate-release tablet of topiramateanti epileptic drug. J Pharm Sci Biosci Res 2013;3:77-90.

2. Darwhekar GN, Jain DK, Chouhan J. Biopharmaceutical classification of candesartan and candesartan cilexetil. Asian J Pharm Life Sci 2012;2:295-302.

3. Jagtap S, Magdum C, Jadge D, Jagtap R. Solubility enhancement technique: a review. J Pharm Sci Res 2018;10:2205-11.

4. Jaiswal M, Dudhe R, Sharma PK. Nanoemulsion: an advanced mode of drug delivery system. Biotechnology 2015;5:123-7.

5. Chouksey R, Jain AK, Pandey H, Maithil A, College GM, Satya S, et al. Development and bioavailability studies of atorvastatin nanoemulsion. Int J Pharm Life Sci 2011;2:982-8.

6. Abo Enin HA. Self-nano emulsifying drug-delivery system for improved oral bioavailability of rosuvastatin using natural oil antihyperlipidemic. Drug Dev Ind Pharm 2015;41:1047-56.
7. Zhang $\mathrm{Y}$, Shang $\mathrm{Z}$, Gao $\mathrm{C}, \mathrm{Du} \mathrm{M}, \mathrm{Xu} \mathrm{S}$, Song $\mathrm{H}$, et al. Nanoemulsion for solubilization, stabilization, and in vitro release of pterostilbene for oral delivery. AAPS PharmSciTech 2014;15:1000-8.

8. Mantena AD, Dontamsetti BR, Nerella A. Formulation, optimization and in vitro evaluation of rifampicin nanoemulsions. Int J Pharm Sci Drug Res 2015;7:451-5.

9. Husain A, Mitra MSA, Bhasin PS. A review of the pharmacological and pharmaceutical profile of irbesartan. Pharmacophore 2011;2:276-86.

10. Sisinthy SP, Rao NK, Sarah CYL. Design, optimization and in vitro characterization of self nano emulsifying drug delivery system of olmesartan medoxomil. Int J Pharm Pharm Sci 2016;9:94.

11. Araujo AAS, Bezerra $M$ dos S, Storpirtis S, Matos J do R. Determination of the melting temperature, the heat of fusion, and purity analysis of different samples of zidovudine (AZT) using DSC. Brazilian J Pharm Sci 2010;46:37-43.

12. Poluri K, Sistla RK, Veerareddy PR, Narasu ML. Formulation and preparation of felodipine nanoemulsions. Asian J Pharm Clin Res 2011;4(Suppl 1):116-7.

13. Ghareeb MM, Neamah AJ. Formulation and characterization of nimodipine nanoemulsion as ampoule for oral route. Int J Pharm Sci Res 2017;8:591-602.

14. Chhabra G, Chuttani K, Mishra AK, Pathak K. Design and development of nanoemulsion drug delivery system of amlodipine besilate for improvement of oral bioavailability. Drug Dev Ind Pharm 2011;37:907-16.

15. Chidi E. Development and evaluation of nanoemulsion formulations for improved oral delivery of carvedilol. Univers J Pharm Res 2018;2:5-11.

16. Sharma N, Mishra S, Sharma S, Deshp RDe, Sharma RK. Preparation and optimization of nanoemulsions for targeting drug delivery. Int J Drug Dev Res 2009;5:37-48.

17. Singh KK, Vingkar SK. Formulation, antimalarial activity and biodistribution of oral lipid nanoemulsion of primaquine. Int J Pharm 2008;347:136-43. 
18. Khachane PV, Jain AS, Dhawan VV, Joshi GV, Date AA, Mulherkar R, et al. Cationic nanoemulsions as potential carriers for intracellular delivery. Saudi Pharm J 2015;23:188-94.

19. Drais HK, Hussein AA. Formulation and characterization of carvedilol nanoemulsion oral liquid dosage form. Int J Pharm Pharm Sci 2015;7:209-16.

20. Ramakrishna S, Mihira V, Raja Vyshnavi K, Ranjith V. Design and evaluation of drug release kinetics of meloxicam sustained release matrix tablets. Int J Curr Pharm Res 2012;4:90-9.

21. Shakeel F, Haq N, Ali M, Alanazi FK, Alsarra IA. Impact of viscosity and refractive index on droplet size and zeta potential of model 0/W and W/O nanoemulsion. Curr Nanosci 2013;9:248-53.

22. Ali $\mathrm{HH}$, Hussein AA. Oral nanoemulsions of candesartan cilexetil: formulation, characterization and in vitro drug release studies. AAPS Open 2017;3:1-16.

23. Arora R, Aggarwal G, Harikumar SL, Kaur K. Nanoemulsion based hydrogel for enhanced transdermal delivery of ketoprofen. Adv Pharm 2014;1-12. http://dx.doi.org/10.1155/2014/468456

24. Karthikeyan S, Jeeva PA, Jerobin J, Mukherjee A, Chandrasekaran N. Formulation and characterization of nanoemulsion coatings from Azadirachta Indica. Int J ChemTech Res 2012;4:1566-70.

25. Thirupathi A, Meshram S, Sampathi S. Solid state characterization of the polymorphic changes in candesartan cilexetil solid dispersion with polyethylene glycol 8000. Int J Pharm Sci Res 2014;6:27-32.

26. Kamalakkannan V, Puratchikody A, Ramanathan L. Development and characterization of controlled release polar lipid microparticles of candesartan cilexetil by solid dispersion. Res Pharm Sci 2013;8:125-36.

27. Asdaq SM, Inamdar MN. Potential of garlic and its active constituent, S-allyl cysteine, as antihypertensive and cardioprotective in the presence of captopril. Phytomedicine 2010;17:1016-26.

28. Ngan CL, Basri M, Tripathy M, Karjiban RA, Abdul Malek E. Physicochemical characterization and thermodynamic studies of a nanoemulsion-based transdermal delivery system for fullerene. Sci World J http://dx.doi.org/10.1155/2014/219035

29. Guttoff M, Saberi AH, Mcclements DJ. Formation of vitamin D nanoemulsion-based delivery systems by spontaneous emulsification: factors affecting particle size and stability. Food Chem 2015;171:117-22.

30. Elmarzugi NA. Preparation and evaluation of olive oil nanoemulsion using sucrose monoester. Int J Pharm Pharm Sci 2013;5:434-40.

31. Honary S, Zahir F. Effect of zeta potential on the properties of nano-drug delivery systems-a review (Part 2). Trop J Pharm Res 2013;12:265-73. 